SINAI Journal of Applied Sciences 9 (2) $2020 \quad 247-258$

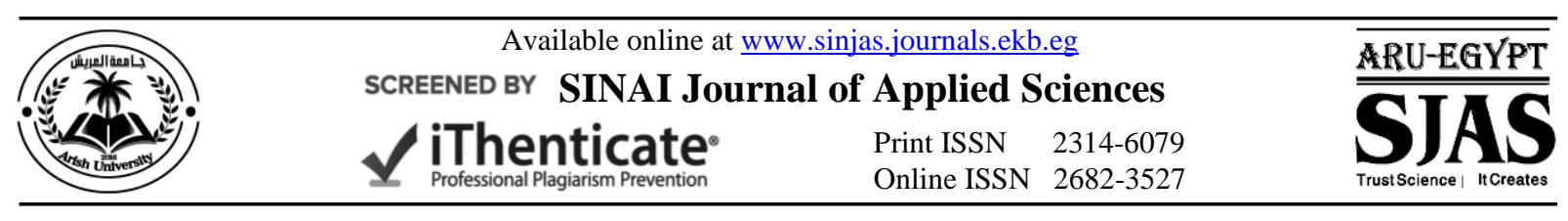

\title{
ALTERNATIVE STRATEGIES FOR DEVELOPING DESERT LOCUST MANAGEMENT IN EGYPT: SWOT ANALYSIS
}

\author{
Tamer A. Abu Qandil ${ }^{1}$, M.M. Hassan ${ }^{2}$, M.A. EISayed ${ }^{2}$, RI. Radwan ${ }^{2}$ \\ 1. General Dept. Locust and Agric. Aviation Affairs, Minist. Agric. and Land Reclam., Egypt. \\ 2. Dept. Econ. and Rural Develop., Fac. Environ. Agric. Sci., Arish Univ., Egypt
}

\begin{tabular}{l} 
ARTICLE INFO \\
\hline Article history: \\
Received: $26 / 06 / 2020$ \\
Revised: 03/07/2020 \\
Accepted: 03/07/2020 \\
Available online: 03/07/2020 \\
\hline Keywords: \\
SWOT analysis, \\
Desert Locust Management, \\
strategy, \\
Egypt.
\end{tabular}

Egypt.

\begin{abstract}
The main objective of the SWOT analysis method for Desert Locust Management in Egypt to develop a new future strategic vision for its development through the following factors: Determine strengths and weaknesses in internal environmental factors, Identification of points of opportunity and threats in external environmental factors. In order to accomplish this, reliance was made on Locust Management bases and Desert Locust Research Centre, a work group has also been formed for environmental analysis in the internal and external environment, about 73 individuals distributed to experts involved in the field of research, the results show that the most important strengths of Locust Management in Egypt are: The presence of trained technical and research cadres in the Locust Operations Management, and the existence of the contingency plan for emergency intervention. Whereas one of the most important weaknesses was the lack of concern about the size of the problem and the real estimate of Locust numbers and their size, that led to accelerate the worsening of the crisis. Lack of awareness to deal with Locust swarms leads to their dispersal, which is difficult to deal with, also inadequate materials and untrained additional human resources in cases of upsurges and invasions. The results also showed the most important points of opportunity: encouraging the training system to raise the efficiency of staff from other departments, the Locust Control Commission, Regional and International Commissions and donor communities are interested in achieving sustainable development and preserving agricultural crops, benefiting from the experiences of successful countries in the fields of Locust Management. While one of the most important threatening point are: Political unrest in neighbouring countries makes it difficult for survey and control operations especially along the bordering areas, Climate changes and its negative effects in changing the Locust distribution map in Egypt, The inflexibility of the regulations and laws of cooperation between Egypt and the countries of Locusts breeding and invasion for different causes, especially with neighbouring countries. The study, through the analysis of the SWOT matrix, found the most important policies to develop the performance of Desert Locust Management in Egypt in the following: to benefit from the experiences of successful countries in the fields of Locust Management by collaborating with the Commission for Controlling the Desert Locust in the Central Region to provide information, technical and financial support to the Locust Management, based on the experiences of these countries, A real estimate of the scale of the problem and Locust infections and the raising of sufficient awareness of citizens to deal with swarms, which reduces the worsening of the crisis, encourage the training system to compensate the inefficiency and inadequate staff and additional teams from other departments to cope with upsurges and invasions, and developing an extension programs for citizens' dealings with Locust swarms, especially in areas of horizontal expansion in agriculture or areas where Locusts are expected to be present as a result of climate changes. The study proposes a new vision for the development of the General Department for Locust Affairs in Egypt and its efficiency in serving the agricultural sector to contribute to food security and sustainable agricultural development.
\end{abstract}

\footnotetext{
* Corresponding author: E-mail address: tmrkandel@yahoo.com https://doi.org/10.21608/SINJAS.2020.33897.1000

(C) 2020 SINAI Journal of Applied Sciences. Published by Fac. Environ. Agric. Sci., Arish Univ. All rights reserved.
} 


\section{INTRODUCTION}

The agriculture sector considered as one of the most important sectors in the Egyptian economy due to its vital and effective role in economic activity. This sector has witnessed a significant development during the past period due to the introduction of modern and advanced technological aspects, which reflected in the rise of this sector in general and the increase in the production of acre of most agricultural crops in particular. It is also the main focus of progress, growth, development and achievement of the quality of its content, because it contains the potential and developmental capabilities; it is a vast area that expands and offers everything in its way to achieve comprehensive development if the latest innovations provided by science are utilized (Specialized National Councils, 1990).

The modernity of agriculture is the main element of the concern for the officials of the Egyptian Agricultural Sector to raise the level of living and achieve a better living of rural and city residents. In order to do so, it was necessary to establish a mechanism to keep agricultural crops from the threat of plant pests and diseases that affecting negatively the productivity of the acre, bearing in mind that Desert Locusts are one of the most dangerous pests that are devastating severely the plant crops. The areas controlled due to the Desert Locust invasion in Egypt amounted to about 106.3 thousand hectares in 2005, while in 2013 it was 36.6 thousand hectares (The Food and Agriculture Organization of the United Nations, different numbers).

The Management of Desert Locust operations is one of the most important directorates pursued by the Arab, African and Asian states located within the path of Desert Locust swarms. FAO has emphasised special attention to the problem of Desert Locusts and has assigned specialised commissions that provide technical, financial and technological development support to countries affected by Desert Locusts and urge donor communities to direct their support to reduce the effects of Desert Locusts in developing countries. Losses will be around $\$ 8.5$ billion in Locust-affected countries by the end of 2020, according to FAO estimates (Holger Kray, 2020).

The need for change in economic and service organizations generally arises as a result of the fact that there is a gap between the objectives for which it was created and between the expectations desired. This gap is usually due to poor handling of everchanging bio-factors and these factors may be external, such as climatic factors, technological, political, legal and resourcerelated factors. They may be internal factors such as the change of staff thought, the inadequacy of the structure and the arrangement of the organization, so the administration should try to make some changes that achieve compatibility with its environment (Al-Zuhairi, 2008). In order for the Desert Locust Management to play its natural role and contribute to the economic development process to achieve primarily the food security of the country, this necessitated a regulatory development of a strategy and a set of regulations and rules governing the work in the General Directorate of Locust Affairs, with the removal of all financial, administrative and routine constraints that limit the performance of Locust operations Management.

\section{RESEARCH PROBLEM}

In recent years, Locust Management has been facing stagnation as a result of the events and changes (local and regional) experienced in the region, resulting in the emergence of many severe and chronic problems and constraints in the administrative system of the State. This has been reflected in the duties performed by the staff of the General Directorate of Locust Affairs, which has led to a decrease 
in the level and efficiency of survey and control operations in most cases, as well as the deterioration and low efficiency of operations associated with Desert Locusts. Consequently, it has become necessary to reform and renew the General Directorate of Locust Affairs in order to be able to carry out its tasks and to narrow the technological gap between the results of scientific research and practical application on ground.

\section{RESEARCH OBJECTIVES}

In line with the research problem, the research aims to develop a new vision and missions for developing Locust Management through the achievement of the following objectives:

1. Study of the internal factors of Desert Locust Management.

2. Study of external factors of Desert Locust Management.

3. Develop a vision and a new message for developing Desert Locust Management.

\section{RESEARCH AREA}

This research was conducted at the level of 13 main bases and sub-bases with survey teams at the level of the Republic, including: the headquarters of the General Directorate of Locust Affairs and Agricultural Aviation at the Ministry of Agriculture in Cairo. The main bases of Ismailia, Suez, El-Arish (Bir al-Abd), ElTur, Assiut, Qena, Aswan (Abu Ramd, Shalatin, Sheikh El-Shazly and Abu Sampple), The New Valley (Al-Kharja, Dakhla and East Al-Aweinat), Sea Oases, Marsa Matrouh (Salloum and Sidi Barani), Tanta and Mansoura.

\section{RESEARCH SAMPLE}

The research sample was formed for environmental analysis of individuals in the internal and external environment that are involved to work in the field of Locusts through a class sample of about 73 individuals distributed as described in Table 1. The final list was then submitted to 10 experts involved in Locust Management from the same sample for their full knowledge of the questionnaire. Also some faculty members involved in research from the Faculty of Agricultural and Environmental Sciences, Al-Arish University, were also used to review the questionnaire before distributing it to the researchers.

\section{RESEARCH METHOD AND DATA SOURCES}

The research relied on four-way environmental analysis, which is the best way to link the results with each other and benefit from them. The method depends on the determination of strengths and weaknesses and the determination of opportunities and threats and thus come up with a clear action plan to develop Locust Management and develop a vision and a new message for the development of Locust Management. The main question is to look into what are the instruments of the development of Locust Management in Egypt?

The collection of data was based on the design of a questionnaire containing a set of strengths and weaknesses, as well as a set of points of opportunity and threat. The conclusion was drawn from the results of discussions and deliberations with some specialists and the Director General of the General Department of Locust Affairs and professors from the Faculty of Agricultural and Environmental Sciences (Valkov, 2010). The questionnaire is of a diverse type (closed/open) with a number of phrases under each area, leaving the opportunity for participants to add other points. The relative weight or relative importance of each term was calculated by dividing the number of those who chose this term by the total number of the sample (73 researches) and thus ranging the weight from (1) or $100 \%$ "most important" to (0) or $0.0 \%$ "not important". The collection of the data lasted about two years from November to December 2019. 
Table 1. Distribution of Researchers and Experts Involved in Environmental Analysis

\begin{tabular}{llc}
\hline Environment & \multicolumn{1}{c}{ Category } & No. \\
\hline Internal & - Agricultural specialist and technician & 55 \\
& - Technician repair and maintenance of sprayers & 5 \\
& - Director General of the General Directorate of Locust Affairs & 1 \\
External & - Current and former Executive Secretary of the Desert Locust & \\
& Control Authority & 2 \\
& - Technical Assistant of the Desert Locust Control Authority & 1 \\
Total & - Professor and researcher from the Locust Research Centre & 9 \\
\hline
\end{tabular}

\section{RESULTS AND DISCUSSION}

Results of environmental analysis (SWOT) for the development of Desert Locust Management in Egypt (Houben $\boldsymbol{e t}$ al., 1999):

1. After presenting the questionnaire to the 73 researchers, the results of the internal environment of Desert Locust Management in Egypt revealed the following:

a. Strengths points (15)

b. Weaknesses points (20)

2. The results of the external environment of Desert Locust Management in Egypt also revealed the following:

a. Points representing opportunities (12)

b. Points representing threat (12)

3. After compiling the opinions of the researchers, the final list of the SWOT matrix was determined by identifying 10 points representing the strengths and weaknesses of the internal environment strategy and 10 points representing the points of opportunity and threats in the external environment strategy, which is the top 10 phrases that were weighted by the researchers. That is, after calculating the relative importance (weight) of each phrase, the most important was chosen on each side so that the final matrix was formed (Valentin, 2005).

4. The final list was then presented to 10 experts involved in Locust Management, and they are:

- Current and former Executive Secretary and Technical Assistant of FAO Commission for Controlling the Desert Locust in the Central Region,

- Director General of the General Directorate of Locust Affairs and Agricultural Aviation,

- Director of the General Directorate of Locust Affairs and Agricultural Aviation,

- Director of information department at the General Directorate of Locust and Agricultural Aviation,

- Training Officer, General Directorate of Locust Affairs and Agricultural Aviation,

- Three professor doctors at the Locust Research Centre.

They were requested to give each strategic factor a degree that would determine the efficiency or ability of the institution at present to deal with this factor, and this degree was determined on a scale of five degrees. The degree (5) reflects a 
distinct response and a degree (1) reflects weak response (Menga et al., 2013).

5. Weights, which represent the weight gain of each factor in the column, were calculated in the degree obtained by this factor, accordingly, the internal environment strategy, external environment strategy and alternative strategies (Wright and McMahan, 1992) were formed as follows:

Step 1: Analysis of internal strategic factors for the working environment of Locust Management staff (Ibrahim, 2008; Ahmed, 2008) - Table (2)

Table 2. Analysis of internal strategic transactions of the Desert Locust Management

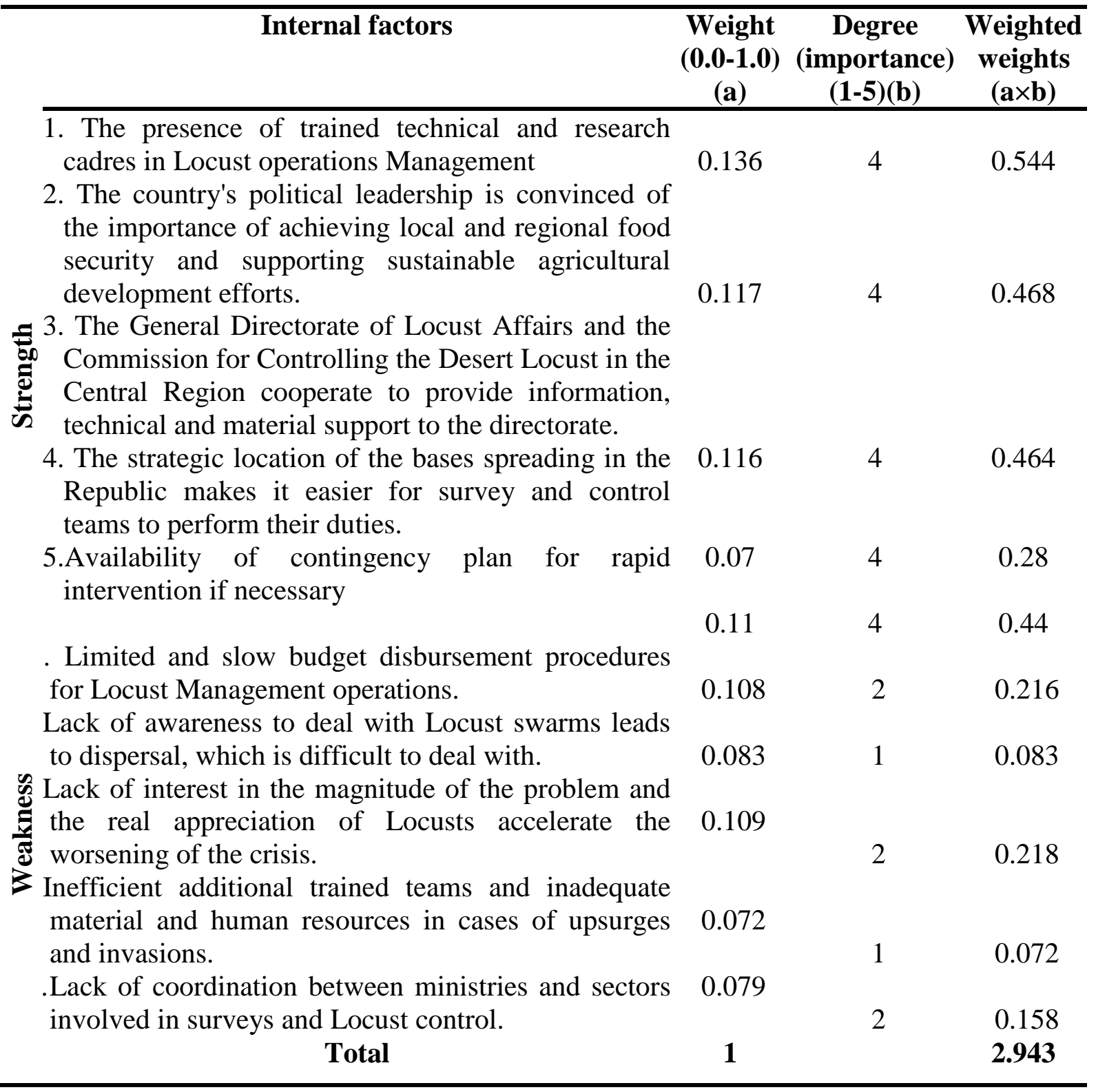

Source: Collected and calculated from Locust Management field study data, 2019. 
Step 2: Analysis of external Locust Management factor for staff working environment (Ahmed, 2008) - Table (3)

Table 3. Analysis of external strategic Management factors for Desert Locust Management

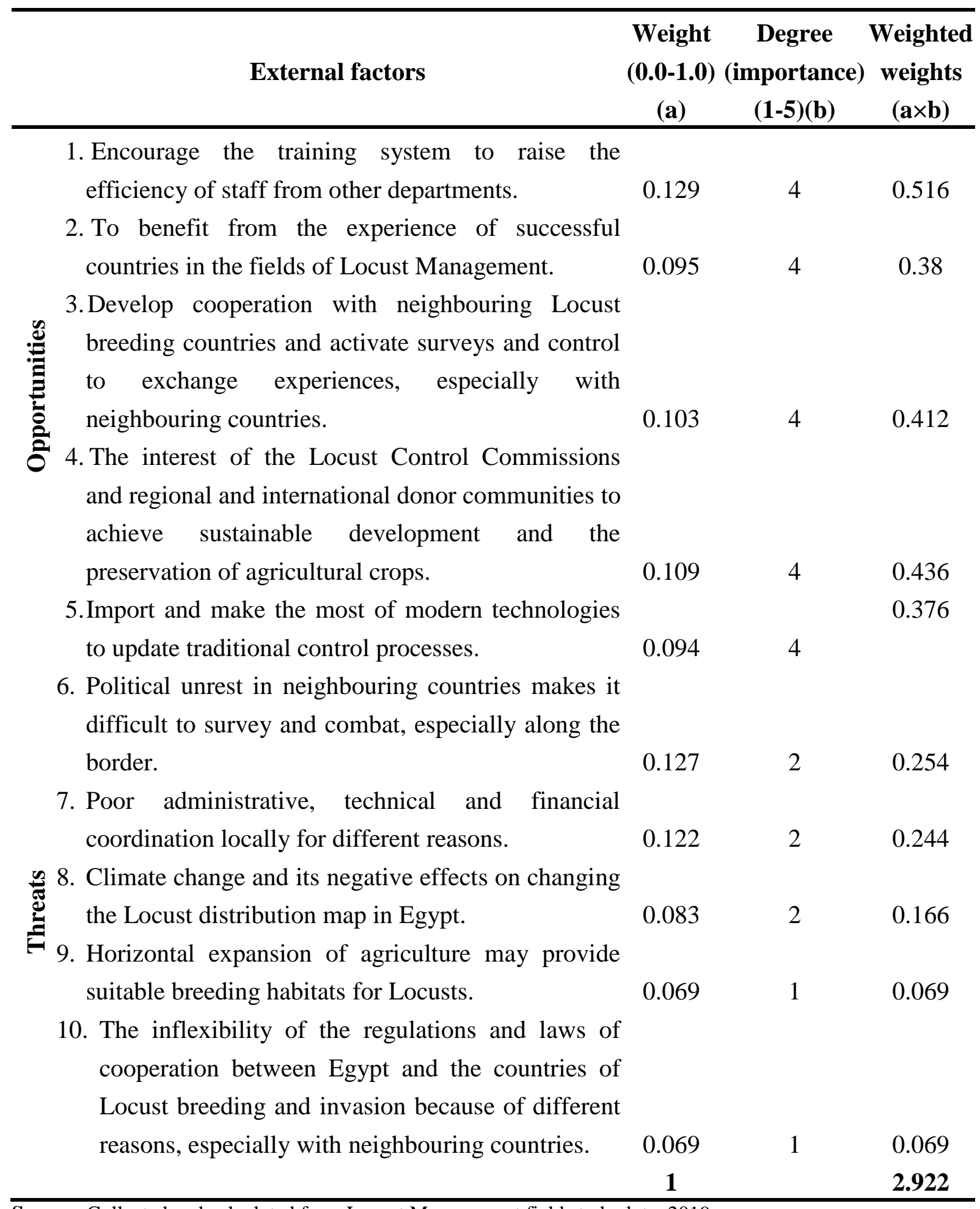


6. Weights weighted for each variable were collected to determine the overall score of the organization, and if the total weights weighted are less than 2 then the organization's performance is poor and at the same time indicates that the officials do not have sufficient awareness of the strengths and weaknesses within their organization, If the total weights are close to 3 , this indicates that the performance of the organization is average and that the officials are aware of the strengths and weaknesses within their organization. Thus, the chances and potential of the development of this institution and its ability to achieve its goals and targets in the future increases, but if the value of the total weights weighted is close to 5 , this indicates that the performance of the organization is excellent (Sanhouri, 2013).

The relative importance (Total weighted weights) of the internal environment strategy was 2,943 while it was about 2,922 for the external environment strategy, which means that the performance of Locust Management in Egypt is average and that its employees have sufficient awareness of the strengths and weaknesses. Also they have the ability to identify the opportunities and threats that may be directed at Locust Management in Egypt, which gives a good indication and hope that there is a great opportunity to develop Locust Management in Egypt, provided that the appropriate human and material resources and organizational and administrative matters of regulations and laws to improve working conditions.

Step 3: Develop alternative strategies using the quadruple Analysis Matrix (TOWS) to develop the performance of Desert Locust Management in Egypt (Vanêk et al., 2012)

After preparing internal and external environmental factors, the quadruple analysis system matrix can be established as described in table (4) to develop the performance of Desert Locust Management, and the matrix refers to four types of strategies as follows:

- Weakness and Threat Strategy (WT): It is generally aimed at reducing weakness factors and avoiding threats.

- Weakness and Opportunity Strategy (WO): It is generally aims to reduce weakness and increase opportunities.

- Strength and Threat Strategy (ST): It is based on the strength that can handle risk transactions in the environment and aims to increase strength and reduce risk transactions.

- Strength and Opportunity Strategy (SO): It is generally aiming to increase strength and opportunity factors. The study, through analysis of the SWOT/TOWS matrix, found the following most important strategies for developing the performance of Desert Locust Management, as described in Table 4:

\section{A Vision and Missions for Desert Locusts Management in Egypt}

From the results of the research and the matrix of SWOT analysis, a vision and missions for the Management of Desert Locusts in Egypt can be formulated as follows:

\section{Vision}

General Directorate of Locust Affairs in Egypt seeks to achieve leadership and excellence in serving the agricultural sector in particular and society in all categories in general.

\section{Mission}

General Directorate of Locust Affairs in Egypt is committed to its human resources and qualified expertise of engineers and technicians to protect the Egyptian agricultural sector through continuous development and planning of survey, control and information programs. This is based on the actual needs of the local community in particular and developments in the regional situation in general. 


\section{Table 4. TOWS analysis matrix for development of Desert Locust Management}

\begin{tabular}{ll}
\hline Internal & Strength (S) \\
Environment & S1: The presence of trained technical \\
& and research cadres in the \\
& Management of Locust operations
\end{tabular}

S2: The political leadership of the state is convinced of the importance of achieving local and regional food security and supporting sustainable agricultural development efforts.

S3: The cooperation of the General Directorate of Locust Affairs and the Commission for Controlling the Desert Locust in the Central Region to provide information, technical and financial support to the directorate.

S4: There is a contingency plan for emergency intervention.

S5: The strategic location of the bases deployed in the Republic makes it easier for survey and control teams to perform their duties.

\section{Opportunities (O)}

01: Encourage the training system to raise the efficiency of staff from other departments.

O2: To benefit from the experience of successful countries in the fields of Locust Management.

O3: Develop cooperation with neighbouring Locust breeding countries and activate surveys and control to exchange experiences, especially with neighbouring countries.

04: The interest of the Locust Control Commissions and regional and international donor communities to achieve sustainable development and the preservation of agricultural crops.

05: Import and make the most of modern technologies to update traditional control processes.
Strength/Opportunities (S/O)

\section{$\mathrm{A}: \mathrm{S1}+\mathrm{O1+O5}$}

To benefit from the presence of trained technical and research personnel in the Management of Locust operations by raising their efficiency by training in modern techniques that are imported to update the traditional control processes and make the most it.

\section{$\mathrm{B}: \mathrm{S} 2+\mathbf{O 2}+\mathbf{O 3}$}

To benefit from the conviction of the political leadership of the state and the interest of the Commission for Controlling the Desert Locust in the Central Region as well as regional and international donor communities to develop cooperation with neighboring countries accommodating Locust breeding habitats and support and activate joint surveys and control processes to exchange experiences

\section{$\mathrm{C}: \mathrm{S3+O4}$}

To benefit from the experience of successful countries in the fields of Locust Management by collaborating with the Commission for Controlling the Desert Locust in the Central Region to provide information,

\section{Weakness (W)}

W1: The lack of interest in the magnitude of the problem and the real estimate of Locusts accelerate the worsening of the crisis.

W2: Limited and slow budget disbursement procedures for Locust Management operations.

W3: Lack of coordination between ministries and sector involved in Locust survey and control operations.

W4: Lack of awareness to deal with Locust swarms leads to dispersal, which is difficult to deal with

W5: Inefficient additional trained teams and inadequate material and human resources in cases of upsurges and invasions.

\section{Weakness/Opportunities (W/O)}

\section{A: W1+W4+O4}

To benefit from the experiences of successful countries in the fields of Locust Management, which are concerned with real estimate of the scale of the problem and Locust infections and to raise enough awareness among citizens to deal with swarms, which reduces the worsening of the crisis.

\section{B: $\mathrm{W} 2+02$}

Take advantage of the interest of the Commission for Controlling the Desert Locust in the Central Region and international and regional donor communities to achieve sustainable development to partially compensate for the limited budget procedures allocated to Locust Management operations.

\section{C: W5 +01}

Encourage the training system in order to compensate for the inadequate and inefficiency of staff in case additional teams needed from other departments to cope with upsurges and invasions. 
technical and financial support to the General Department of Locusts on the experiences of these countries.

\section{D: W5 +O5}

Make the most of modern techniques to update traditional control processes to compensate for the inadequacy and efficiency of additional human and financial resources.

\section{Weakness and Threats (WT)}

\section{Threats (T)}

T1: Political unrest in neighboring countries makes difficult to survey and control especially along the borders.

T2: Poor administrative, technical and financial coordination locally with different causes.

T3: Climate change and its negative effects to change the Locust distribution map in Egypt.

T4: Horizontal expansion of agriculture may provide suitable breeding habitats for Locusts.

T5: The inflexibility of the regulations and laws of cooperation between Egypt and the countries of Locust breeding and invasion because of different reasons, especially with neighbouring countries.

\section{Strength and Threats (ST)}

\section{A: S2+T2}

Taking advantage of the conviction of the political leadership of the state, of the importance of achieving local and regional food security and convincing it to establish regulations for the Management of Locusts to counter the weakness of administrative, technical and financial coordination.

\section{B: S3+T1+T4}

Cooperation of the General Directorate of Locust Affairs and the Commission for Controlling the Desert Locust in the Central Region, to provide information, technical and financial support to the administration to compensate for the inflexibility of the regulations and laws of cooperation between Egypt and the countries of accommodate Locust breeding habitats and invasion. Also, to provide information on Locusts in neighboring countries where there are political unrest

\section{$C: \mathrm{S} 4+\mathrm{T} 1+\mathrm{T} 3+\mathrm{T} 4$}

The existence of a contingency plan for rapid intervention when necessary, as a result of the negative effects of climates change and horizontal expansion of agriculture. This may provide suitable environments for Locust breeding as well as political unrest of neighboring countries, where it is difficult to survey and control, especially at the border.

\section{D: S5+ T3+T4}

Focus on surveys from strategic bases close to areas of horizontal expansion in agriculture or potentially may developed as a result of climate changes that may provide new environments suitable for Desert Locust breeding. Establishment of new bases in areas where there are no bases.

\section{A: W1+T1}

Develop innovative solutions for survey and control operations along border areas with neighbouring in Locusts breeding countries that are in political turmoil so that the lacks of attention to the problem of Locust situation in these areas do not accelerate the worsening of the crisis

\section{B: $\mathbf{W} 3+\mathrm{T} 2+\mathrm{T} 4$}

Develop an internal mechanism for administrative, technical and financial coordination within the Ministry of Agriculture and the Department of Locust Affairs, and between the directorate and other departments and ministries involved in survey and control operations. And to develop a mechanism for external coordination to establish regulations and laws for cooperation with the countries of Locusts breeding and invasion habitats, especially with neighbouring countries in the areas of surveying and controlling Desert Locusts

\section{C: W4+T3+T4}

Developing awareness and extension programs for citizens' dealings with Locust swarms, especially in areas of horizontal expansion in agriculture or areas where Locusts are expected to be present as a result of climate changes. 


\section{REFERENCES}

Specialised National Councils (1990). Horizontal Agricultural Expansion, Technical Report No. 8, Cairo.

Patrick, M.W. and Gary, C.M. (1992). Theoretical Perspectives for Strategic Human Resource Management, J. Manag., 18 (2): 295-320.

Houben, G.; Lenie, $K$. and Vanhoof, $K$. (1999). A Knowledge-based SWOTAnalysis System as an Instrument for Strategic Planning in Small and Medium Sized Enterprises, J. Decision Support Systems, 26 (2): 125-135.

Valentin, E.K. (2005). A way with SWOT Analysis: Use Defensive/ Offensive Evaluation Instead, Theory and Practice. J. Appl. Business Res., 21(2): 54.

Ahmed, H.M. (2008). Strategic Management, Concepts and Models, United Arab Marketing and Supplies Company, Cairo, 79.

Al-Zuhairi, I.A. (2008). School and Classroom Management. Comprehensive Quality Perspective, Arab Thought House, 193-194.
Valkov, A. (2010). Ten Mistakes at the Usage of SWOT -Analysis in the Strategic Marketing Planning in the Healthcare Inst., Econ. Alternatives, Univ. Nat. and World Econ., Sofia, Bulgaria, 1: 93-103.

Vanêk, M.; Milan, M. and Kateřina, Ž. (2012). Evaluation Methods of SWOT Analysis, Metody Vyhodoceni SWOT Analysis, Geo Sci. Eng., LV111, 2: 2331.

Menga, E.; Dan, A. and Liu, X. (2013). The use of Axiomatic Fuzzy Set Theory in the AHP and TOPSIS Methodology to determine Strategies Priorities by SWOT Analysis, Qual Quant, 47: 2671.

Sanhouri, M.M. (2013). Strategic Manag., Univ. Thought House, Alex., 124-149.

Holger, K. (2020). Director of Agriculture and Food Security, World Bank Donuts, 14 April.

United Nations Food and Agriculture Organization (various numbers). The General State of Desert Locusts and Forecasts, Desert Locust Bulletin. 


\section{الملخص العربي}

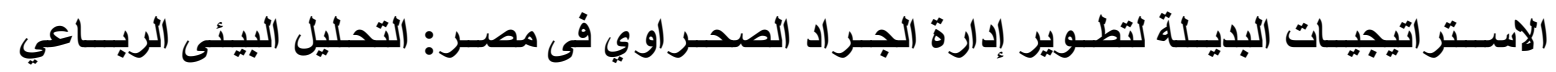

تامر عبدالحميد أبوقنديل1، مروان مصطفي حسن²، محمد أحمد السبد²، رياض مصطفي رضوان 2

$$
\text { 1. إدارة الجر اد الصحر اوي، وزارة الزر اعة و استصلاح الأر اضي، مصر. }
$$

2. قسم الاقتصاد و التتمية الريفية، كلية العلوم الزر اعية البيئية، جامعة العريش، مصر

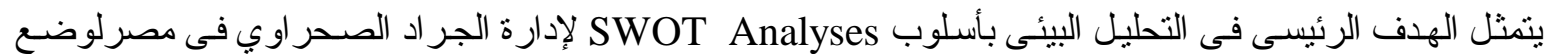

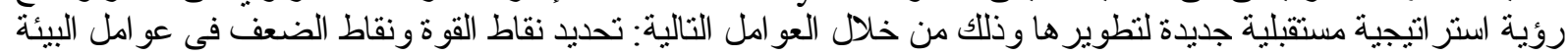

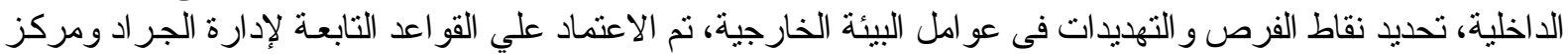

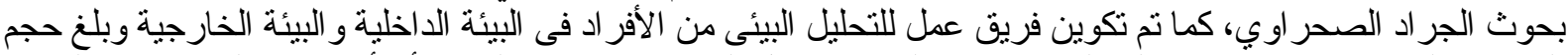

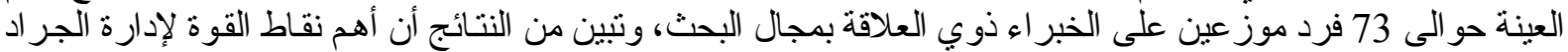

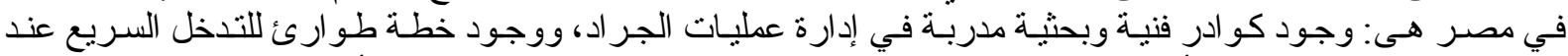

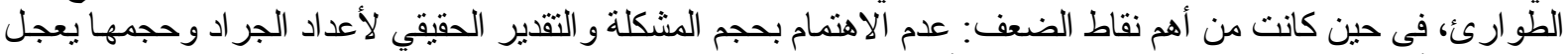

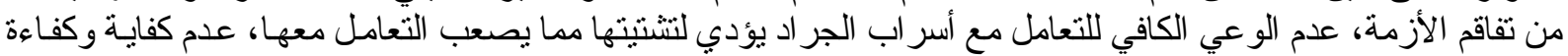

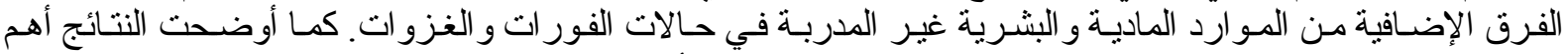

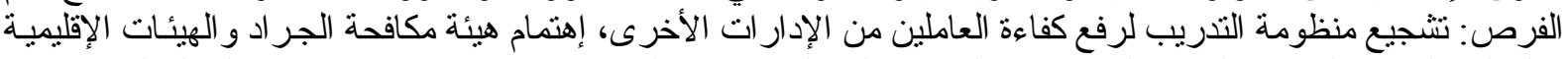

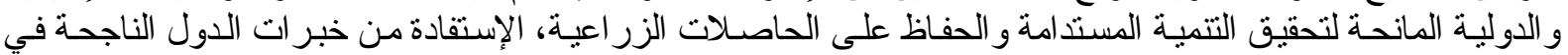

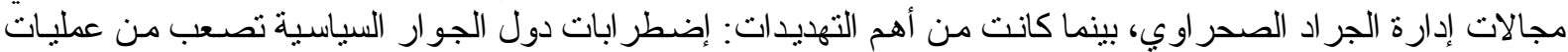

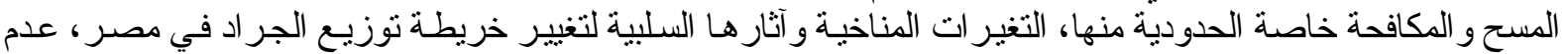

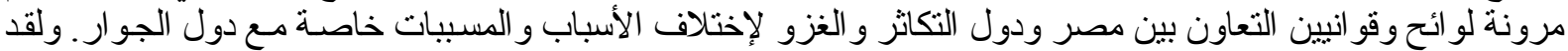

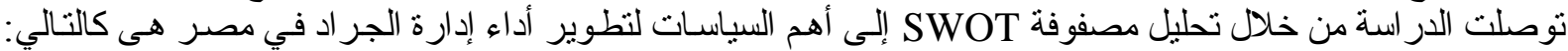

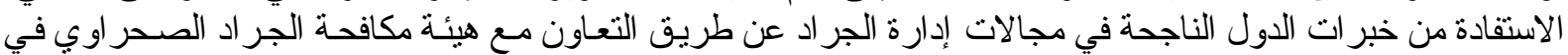

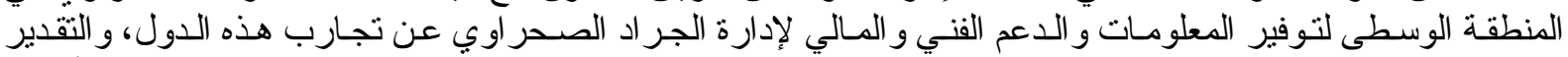

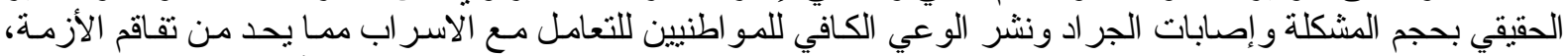

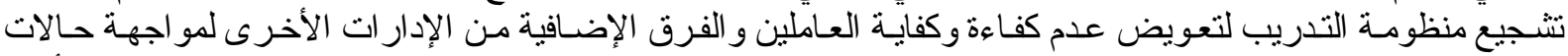

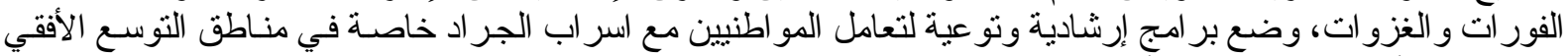

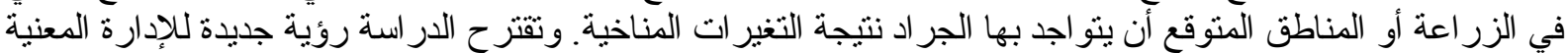

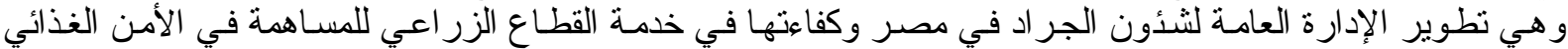
و التتمية الزر اعبة المستخامة. الكلمات الإسترشادية: التحليل البيئى، إدارة الجر اد الصحر اوي، استر اتيجيات، مصر .

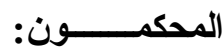

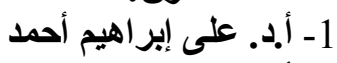

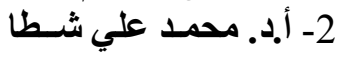


